MATEC Web of Conferences 44, 01080 (2016)

DOI: $10.1051 /$ matecconf/20164401080

(c) Owned by the authors, published by EDP Sciences, 2016

\title{
Research on Chinese Foreign Teaching based on Multimedia Aids
}

\author{
Jie Lu \\ Teacher's College, Beihua University, Jilin, China
}

\begin{abstract}
With rapid development of multimedia aids; Chinese foreign teaching based on the multimedia tools, as a new instructional mode has become a hot topic in online teaching. In this paper, the teaching situation and existing problems by multimedia aids was analyzed by comparing the difference between network teaching platform and traditional classroom teaching. Then the strategy of modernized teaching management and the case, which is focusing on the characteristics of electronic media was present.
\end{abstract}

\section{General instruction}

As China's economic strength and foreign trade, science and technology, cultural exchanges frequently, Chinese as a communication tool, it plays an important role as a bridge in the exchanges between China and the world, the Chinese learning and therefore more and more countries in the world attention. British linguist Mr. David Grando has been published in 1997, "The Future of English" a book predicted that: "the pattern of the world's languages will be restructuring, the Chinese language will be ranked as the world heads strong in the 21 st century, have become language learning."In response to this trend, Chinese Foreign workers actively explore teaching methods, enrich classroom teaching.

Mr. Lv Bisong said: "the language teaching should continue to study teaching methods, produce sound or new teaching methods for each teaching methods are designed to better solve the contradiction between teachings actually exist." Therefore, in order to adapt to the times Development of the new requirements of teaching Chinese Foreign proposed by means of modern technology is used to Foreign Language Classroom Teaching. Among them, the multimedia equipment for the carrier widely used adjunct to classroom teaching middle, and slowly develop into a mature modern teaching model has become the mainstream of contemporary university language teaching hand of foreign language teaching classroom teaching to mature. Research on the use of multimedia in teaching Chinese Foreign very wide, involving classroom teaching as the overall design of classroom teaching methods, HSK test and management courses, but also to teaching, distance learning, multimedia technologies hear, Chinese Application vocabulary, reading, culture and other specific courses based on. The author is in a different class type is mainly the perspective of research on multimedia usage.
Author of Teaching Chinese as a classroom University of Wisconsin summer camp, Shandong University, Shandong Normal University, Tianjin Normal University, Tianjin University of Traditional Chinese Medicine survey found that in a Foreign Language classroom different class of multimedia aids have different practical and applicability. Character education is unique difficulty of making foreign language teaching, and teaching is because of the importance of oral communication level and become the focus of foreign language teaching, the author of both teaching, for example, analyzes the advantages of multimedia teaching and produced problem, and try to come to a solution.

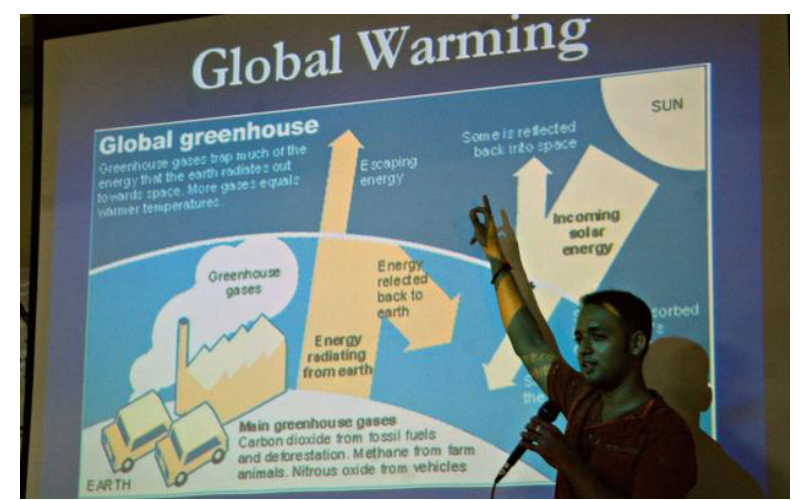

Figure 1. Foreign Language classroom different class of multimedia aids

This study of literature, investigation, case law, interdisciplinary studies, comparative studies and other research methods, analysis application status multimedia assisted teaching methods in teaching Chinese Foreign, trying to find a meeting of traditional teaching and multimedia assisted teaching methods point, improving the quality of classroom teaching Chinese as a Foreign. 


\section{Learning theory and multimedia foreign language teaching}

Humans are primarily to get outside information by vision, hearing, touch, smell and taste five different ways, the famous experimental psychologist Rui Tela confirmed by a large number of psychological experiments, five ways in which, 83 per cent of information visual acquisition, $11 \%$ comes from hearing, $3.5 \%$ from the smell, $1.5 \%$ from the tactile, $1 \%$ from the palate. Psychology multidimensional symbol stimulation theory: the amount of information passed multidimensional symbol stimulate greater than the amount of information delivered straight symbol. Chinese characters are two-dimensional, ideographic writing system is sound, form, meaning a combination of alphabetic writing is much greater, it presents information than linear line structure. This suggests that when learners of Chinese characters, when the amount of information received, psychological resource consumption is also great, mobilize more neurons. Sheen universe had compared the situation when English reading eye movement, he believes that the differences in English reading space allocation when different eye gaze. Single square structure and a plurality of kanji characters combined square combination line, so that each row of Chinese characters reading at times when you want to watch more English to read the number. Due to the special nature of the characters themselves, which determines the learner in the learning of Chinese characters in the process, the energy and stamina to pay more than ideographic writing system to pay for energy, environment and therefore need outside help, from various angles on them sensory stimulation, so that they can more easily and effectively learn Chinese characters.

As psychologists study of human learning process Cognitive Law deepening awareness of people continue to strengthen self-learning, constructivist theory became popular. Constructivism is a branch of cognitive learning theory, which emphasizes the cognitive subject of internal psychological processes, and the learner is seen as the main body of information processing, it is very different and behavioural learning theory. Behavioural learning theory emphasizes "stimulus-response", and the learner regarded as passive response to external stimuli, that is, as knowledge instil object. The constructivist theory holds that learning is situational, social and constructive, knowledge is not obtained by the teachers teach, but learners in certain situations namely social and cultural background, with its outside help, such as a teacher or a friend, use the necessary learning materials, through the construction of ways to get the sense, constructivist learning theory is a further development of cognitive learning theory, mainly the development of cognitive learning theory has some of the "construction" of thought, more emphasis on the students themselves in learning meaning active construction of knowledge, namely that the world is an objective reality, but understanding of the world and give meaning, but it is decided by each person themselves. Students are subject cognition, is the knowledge of the builders. In the process of cognition, the students already have experience on the basis of external information through processing, handling, active construction of meaning external knowledge, to acquire knowledge. Moreover, knowledge is not unique, but development and change, as people know it in-depth and constantly updated, sublimation. Therefore, when the foreign language teachers during the teaching of Chinese characters, not self-centred, but should fully understand the basis of the students' interest and students have some Kanji structure, focused, difficulty properly, individualized, targeted Chinese characters teaching, helping students construct internal character system, so that students in the learning process, and give full play the main role in this active participation on the learner's initiative, enthusiasm to play to create good conditions, that can really reflect the role of the learner's cognitive subject, so that students truly become masters of learning.

\section{External Chinese character teaching multimedia condition}

Character is a kind of form to express the Chinese written language symbol transfer and exchange of information, is an extremely important part of the Chinese, and therefore can not be divorced learning Chinese characters to learn. For foreign students in terms of learning Chinese characters has been adopted by the storm must learn Chinese, European and American countries for the students, the Chinese character is not only a way of writing a different language, or learning from onedimensional linear structure to a two-dimensional block structure symbol symbolic learning change, this learning process is very complicated. Multimedia technology has been widely applied to the Chinese Foreign teaching them and gradually by the people's attention. Multimedia has a storage memory, high-speed computing, logic, automatic operation and other functions, with text, sound, graphics, animation, video and other media information in one, with strong interactivity. Multimedia students through these means, according to the individual learning needs, obtain vivid and intuitive learning materials; you can get rid of the constraints of time past the classroom, and more easily communicate with teachers, get help; you can always assess learning outcomes, optimize learning program, learning to adjust the focus. Thus, the multimedia technology and teaching Chinese Characters combined, enabling Chinese Characters Teaching achieve a multiplier effect.

Non-Chinese students feel difficult to learn Chinese characters, hard one to remember, difficult to recognize, study the fundamental reason, which with the foreign student's mother tongue habits, but this is due to the characteristics of the decision by Chinese characters themselves. Chinese characters are ideographic system, unlike the phonogram; a large number of Chinese characters, complex forms, writing difficult; there are lots of homophones, multi-tone words, words form the past, and most characters can not both phonetic and semantic. The complexity of the characters is information, its 
processing procedures more complex than the phonograph. Single traditional teaching methods, it is difficult to stimulate student interest; ignore the students 'subjective needs, constraints to improve students' ability; lack of input information, for one is not strong. As the traditional way of teaching itself one way or another deficiency, affecting the efficiency of foreign students to recognize and read Chinese characters, so we need to introduce new teaching methods to promote our Chinese Foreign Teaching.

Chinese Characters as a Foreign Language teaching and traditional teaching of Chinese characters the same way, is a teaching means and methods, but the means and methods of teaching and traditional teaching, such as flip charts, compared to the projector, etc., have their own special place. Because it can sound, pictures, animation and other forms of organically combined output at the same time, by way of human-computer interaction to achieve the purpose of teaching. It's an important feature is the ability to maximize stimulate learners senses, attracting the attention of learners, develop their ability to self-learning, thus improving the efficiency of the learner to learn Chinese characters to meet their needs from different levels. Comparison of multimedia teaching of Chinese characters and traditional Chinese characters teaching methods, there are differences between them is obvious.

Learners need to autonomously determine their own learning goals, select appropriate materials, to observe, to think, to imagine, creating a series of activities in order to control the learning process, to become masters of the learning process. Learning to play the main interest is the cognitive power, traditional Chinese Foreign Teaching Since teaching methods and single way, it is easy for students to produce fatigue, and little autonomy of student learning in the classroom passively accept input information, learning Chinese characters interest and potential has not been fully exploited, and multimedia teaching methods due to the comprehensive strengths of the slide projector and other equipment, will be maps, text, sound and Mao, static and dynamic combination of sound and colour, to a greater extent stimulated the students' interest, so that students have a strong desire to learn, so that students in a happy relaxed learning environment to understand the characters of word processing. For example, in explaining the structure of strokes of Chinese characters, can explain the structure of strokes and special treatment, which is, through slow motion, quick release, static display of Chinese characters written order and display the trajectory of strokes of Chinese characters, the direction of movement. After class, since teaching software has many forms of expression, students can help these software, entirely according to their own needs very easily on this information for research and learning, and will not feel dull and boring, always maintained a lot of interest, not the learning of Chinese characters felt a fear, but a positive self-challenge, full of a sense of accomplishment.

\section{Status of Multimedia Foreign Language Teaching Chinese Characters}

At present, many domestic scholars multimedia technology in the teaching of Chinese Characters conducted in-depth studies, such as Lin Hua raised the importance of technical support and multimedia teaching of Chinese character stroke; Wuying Cheng discusses how to use the Chinese character handwriting recognition technology for teaching Chinese characters; Yanghao Liang It discusses the multimedia technology in the teaching of writing Chinese characters, cultural education and strengthen memory teaching three advantages; Liu $\mathrm{Yu}$ analysis of the characteristics of Chinese characters, summarizes the main idea to write Chinese characters font library generation system design and the main algorithm is used. Their articles have pointed out the advantages of multimedia teaching of Chinese characters, and proposed to seize the Chinese character font, etc. to teaching. When we put multimedia technology into the teaching of Chinese Characters, and achieved certain results, it should be noted that some of the problems which arise. Because things are having two sides, multimedia teaching has certain advantages, but improper use can also affect the effectiveness of teaching. Therefore, when we emphasize the application of multimedia technology in the teaching of Chinese Characters when a record can not forget the multimedia technology can not completely replace the traditional teaching role. For example, in the use of multimedia in teaching Chinese characters, ignoring the relevance and moderation, the blind pursuit of visually and trendy, it will have a negative impact on student learning. Therefore, in order to effectively learn Chinese characters, the Chinese Foreign Teaching how reasonable application of multimedia technology, to handle its relations with traditional teaching methods is a new problem that we face.

Emphasis on student-centred teaching philosophy, not to ignore the leading role of teachers in learning; outstanding multimedia many advantages, it is not to deny the teaching of teachers in the Chinese Foreign importance. Multimedia is a teaching tool, the application of multimedia in teaching Chinese as a Foreign Characters, does not mean blindly rely on multimedia and lose instructor in the classroom. Because any kind of teaching activities are inseparable participation and completion of the Teaching of Chinese teachers and students are no exception, and it requires investment in teachers and students together. So, in learning Chinese as a foreign classroom, teachers should give full play to the guiding role, motherhood; students should give full play to the initiative and cultivate awareness of independent learning. Only the two combine, blend, characters can effectively carry out teaching activities. Viewed another way, if the teachers in the use of multimedia techniques, pay attention to train students to analyze problems, problem-solving skills, blind pursuit of visual and auditory stimuli, then, the students had not masters of the classroom, while It is become images, audio, video viewers, ignoring the main classroom content, free 
beyond learning activities. Therefore, the relationship between teachers and multimedia processing, should grasp the "Multimedia is an auxiliary tool, teachers are leading," this principle. Courseware design should focus on the content of classroom teaching, teachers can not be subject to the courseware display, but should be based on the content of teaching and student level, corresponding to demonstrate mastery of courseware content. In the classroom teaching of Chinese characters, according to the students' reaction, the speed of a good grasp of teaching, a good grasp of teaching objectives and teaching content, keeping in mind and student interaction and communication, timely adjustment of classroom content, so good for teaching multimedia services.

\section{Conclusion}

There are many multimedia features, but not each function are suitable for the needs of teaching, the use of multimedia teaching should be consistent with the purpose and content of teaching needs, not simply for the use of multimedia and the use of multimedia. As a foreign language teacher, not only from the students' attention and attract attention, increase interest in this perspective to the classroom use of multimedia. Teachers must clear various functions and various forms of multimedia content is Chinese character teaching services, regardless of whether or not if the form and teaching content related blindly to the pursuit of new ideas, in order to achieve some kind of entertainment at the expense of grandstanding, then, so will bartering distracted the attention of students, so that students because too complex content and loss, thus affecting the efficiency of students learning Chinese characters. Multimedia courseware design should pay attention to targeted, should focus on strengthening students 'visual perception and handwriting capabilities, from the reality of Chinese characters teaching and students, it is necessary to take into account the content of the teaching of Chinese characters, objectives and students' cognitive level, but also consider whether in the classroom to ease of use, but there is no need for picture, sound and playback method used should be no or little use, should try not to be too fancy, make a service to the content.

Students of different levels of hierarchy, different teaching content, teaching different objects, multimedia should be different levels of use. For example, in the high-end conversation class, good multimedia courseware can provide a dialogue scene, guide students to learn, to play the role of go-between; and in the primary listening class, multimedia will not play a big role, but only for audio playback device. Therefore, the use of multimedia teaching should be combined with other teaching methods, without neglecting traditional teaching methods, different teaching methods will be applied to foreign language teaching integrated, seek more reasonable teaching mode to achieve a multiplier effect, which adapt to the current as a Foreign Language teaching. In short, as foreign language teachers, we should be good at thinking and observation, diligent hands, an effective combination of traditional teaching methods in essence with modern multimedia tools applied to teaching practice, in order to achieve the best results of classroom teaching.

\section{References}

1. WANG Xin-wen as a foreign language news to listen to the principles and methods of teaching reading. Applied Linguistics, 56 (2000)

2. Liu Songhao. Listening Teaching Chinese as a Foreign Review World Chinese Language Teaching, $21(2007)$

3. Yang Yuan. Retrospect and Prospect of hearing theoretical research training. World Chinese Language Teaching, 35 (2014)

4. $\mathrm{Yu} \mathrm{Na}$. Teaching Chinese as a review hearing. Educational Research, 12, (2007)

5. Lu station, segment rather expensive. Teaching of Chinese-based multimedia technology. China Educational Technology and Equipment, 84 (2008)

6. Zheng Yanqun research practice a foreign language computer-assisted instruction. Commercial Press, 13 (2006)

7. TURAL multimedia technology on Foreign Language Listening Course of Modern Languages (late), 05 (2006)

8. Feng. Foreign Language Teaching hear the application of multimedia teaching methods. Chinese education technology and equipment, 20, (2008)

9. Chen Zuohong multimedia use Advanced Speaking in Foreign Language Teaching. Research of National Education, 3 (2006)

10. Tang Fuyuan, Xu Lihua Based on Blackboard Teaching Information Technology Discussion Education information, 94 (2005)

11. Han Joan personal knowledge management theory and research. DETAILED DESCRIPTION Jiangsu Nanjing Normal University, 25 (2007)

12. Zhenghan Wen. Cooperative learning classroom management strategies. Wuhan University of Science and Technology, 12 (2006) 